\title{
Antonin Artaud y la Medea de Séneca *
}

\author{
Juan Carlos Sánchez León **
}

\begin{abstract}
RESUMEN ABSTRACT
Este artículo analiza la influencia de las tragedias de Séneca en la filosofía teatral que Antonin Artaud desarrolla entre 1932 y 1936. En su reseña de una adaptación española de Medea representa en México en 1936 (publicada en el diario El Nacional), Artaud explica algunos conceptos teóricos de los manifiestos del «Teatro de la Crueldad" (1932-1933), especialmente la «técnica de la tragedia".

This article analyses the influence of Seneca's tragedies on the philosophy of drama developed by Antonin Artaud between 1932 and 1936. In his review of a Spanish adaptation of Medea performed in Mexico in 1936 (published in the journal El Nacional), Artaud explains some theoretical concepts appeared in the manifestos of the "Theatre of Cruelty" (19321933), specially the «technique of tragedy".
\end{abstract}

* Una primera aproximación a este tema fue presentada en el Simposio «El papel de las Humanidades clásicas en el mundo actual», celebrado en la Universidad Complutense de Madrid los días 10 al 12 de febrero de 1997, organizado por la Sociedad Española de Estudios Clásicos. ** Universidad de Jaén. 
El teatro de Séneca ha influido de forma importante en la filosofía teatral que Antonin Artaud desarrolla entre 1932 y 1936. En los años treinta, Artaud elabora un discurso sobre los grandes mitos antiguos y las fuerzas primordiales de los que su «Teatro de la Crueldad» debía ser una «encarnación». La lectura de las tragedias de Séneca, en especial el Tiestes en diciembre de 1932, ayudaron a Artaud a definir mejor el concepto de crueldad en su teatro a través de un precedente escrito, en un momento en que el público y la crítica parecían no comprender bien este concepto ${ }^{1}$. $Y$, paradójicamente, Artaud se sirve del Tiestes de Séneca, la tragedia antigua más atroz desde el punto de vista de la actuación moral (es decir, la crueldad física como fatalidad cósmica) para establecer el carácter metafísico de su concepto de crueldad en el teatro (es decir, la fatalidad cósmica como crueldad física pero sobre todo como crueldad metafísica).

En cambio, la crítica teatral que Antonin Artaud publicó en el diario «El Nacional» de México en 1936 sobre la representación una adaptación española de la Medea de Séneca, sirvió al dramaturgo para dar su visión del «universo trágico» $y$, sobre todo, para completar y resumir algunos conceptos teóricos definidos en sus Manifiestos sobre el "Teatro de la Crueldad" (1932-1933), en concreto lo que Artaud llama la «técnica de la tragedia», es decir, la «física» del concepto de «crueldad» en el teatro.

\section{LA MEDEA DE SÉNECA EN VERSIÓN DE UNAMUNO, EN MÉRIDA}

La representación de la Medea de Séneca en el Teatro Romano de Mérida por la compañía teatral de Margarita Xirgu el 18 de junio de 1933, fue un éxito de público: a la función asistieron unos tres mil espectadores, la mayor parte de ellos llegados desde Madrid, Barcelona y otras provincias, incluido el mundo oficial, intelectual y artístico de entonces. Relata un periodista en el diario El Sol, 20 de junio de 1933:

"A las siete en punto, en medio de una ovación clamorosa, que ahoga los acordes del Himno de Riego, hace su entrada en el teatro Romano, que presenta un aspecto indescriptible, la comitiva presidencial. Es recibida a la puerta del monumento por sus conservadores, los Sres. Mélida

1 Ver J.C. SÁNCHEZ LEÓN, "A propósito de Séneca y Antonin Artaud: el dossier Atreo y Tiestes", Séneca, dos mil años después. Actas del Congreso Internacional Conmemorativo del Bimilenario de su Nacimiento (Córdoba, septiembre 1996), M. Rodríguez-PANTOJA (ed.), Universidad de Córdoba-CajaSur Publicaciones, Córdoba, 1997, 705-711. 
y García. En primera fila del palco destinado al presidente se sientan con él los dos ministros asistentes al acto, el alcalde de Mérida, los gobernadores general y civil de la provincia, el alcalde de Madrid, el embajador de Italia, y tras ellos, los ayudantes del presidente y los concejales de la ciudad. Al pie de esa presidencia, en el sitio de honor, asimismo, el director de Bellas Artes, que tiene a la derecha e izquierda a los señores Mélida, Unamuno y Macías; D. Teófilo Hernando, presidente del Consejo de Cultura, y demás autoridades... Se hace un silencio de expectación, y la Orquesta Filarmónica, dirigida por el maestro Pérez Casas, e instalada fuera de la escena, a un lado de ella, interpreta magníficamente la obertura de "Ifigenia en Aulis" de Gluck. De la parte del "pulpitum" o escenario desciende Margarita Xirgu, en traje de Medea entonada en rojo y diseñada, como todas las figuras, por su hermano Miguel. A los últimos acordes del preludio, Margarita - Medea - con los brazos en alto, ante la soberbia arquitectura que le da fondo en la clara luz de la tarde, es espléndida estatua viviente. Con voz trémula, que se hincha y ruge y clama, lanza al aire quieto las tremendas imprecaciones de su primer monólogo. La prosa soberbia de Unamuno traduce con decoro soberano la versión de Séneca el cordobés. Medea se duele, herida en su linaje «sfebeo» y en su dignidad de esposa, del abandono de Jasón, que la repudia por casar con Creusa, la hija del rey Creonte. Vuélvese desesperada al palacio, y en el público estalla la primera ovación. Irrumpe en el hemiciclo de la "orchestra" el coro - muchachas ataviadas con túnicas amarillas y capas verdes-, precedido del anciano que lo rige. Sitúase el coro en torno al ara y relata los terribles crímenes de Medea por el amor de Jasón en la expedición de los Argonautas. Danza el coro un ritmo báquico al compás bien medido del "Orfeo» de Gluck. Fundiendo sus voces con la orquesta cantan trinos nupciales en celebración de la boda de la hija del rey Creonte. Al terminar, el público vuelve a aplaudir entusiasmado de la belleza y la finísima claridad del espectáculo que presencia. Nuevamente Medea en escena, discute con Creonte (que viste y representa regiamente Alberto Contreras, precedido y seguido de cuatro esclavos decorativos), le increpa ella, le implora, le pide favor para que la perdone el destierro a que la condena. El rey se retira. Nueva desesperación de Medea, trágicamente bella en las actitudes y el gesto de la Xirgu, en voz doliente y agresiva, en la dicción perfecta, que hace llegar al público, recogido en silencio grave, la dignidad clásica de la empresa de Unamuno, salpicada aquí y allá de misterios y adjetivos inflexibles peculiares del estilo del rector de Salamanca. Nueva intervención del coro, esta vez melancólica, añorante de recuerdos heroicos de mejores tiempos y temores de un negro porvenir. A un lado del hemiciclo, y en lo alto del monumen- 
to, allí donde no se ha permitido por bien entendida precaución el acceso al público, operan los cineastas, el español Alonso y un enviado de la casa Gaumont. El público, absorto, sigue con creciente interés el espectáculo. Enrique Borrás, espléndidamente caracterizado de Jasón, sale a escena por la escalinata, y con voz tonante o tierna, robusta, llana, clara, siempre discute con Medea, rogándole que no vengue en los hijos comunes su odio conyugal. Medea ha recibido el aliento fatal de su instinto y de su destino : en sus propios hijos saciará su furor. Ya el coro, con movimientos distintos de la pausa y del número anterior, más dinámico en su dramatismo, empieza a tomar parte en la tragedia, la música de Gluck cobra, en su lirismo patético, noble dolor. Se ha hecho la noche en el cielo. Los reflectores, colocados en alto a un lado y a otro sobre la escena, iluminan con siniestra claridad la figura de Medea, a quien una esclava, al compás de una flauta que plañe en la orquesta, sirve los menjurjes y venenos para el sacrificio tremendo. Margarita Xirgu, echada en el suelo o erguida, retorciéndose en su desesperación, esgrime el cuchillo vengador. La nodriza (severamente interpretada por Amalia Sánchez Ariño, un poco débil de voz quizá en el bien entonado concierto de sus compañeros), intenta templar una y otra vez en escenas sucesivas el odio de Medea. Ya presagia en un monólogo de largos alientos la desgracia que se cierne fatal, y he aquí que llega la mensajera anunciando el incendio de la ciudad y del palacio por los enemigos de Creonte. Corre tras él el coro, formando con sus actitudes un bello friso. Se tiñe de rojo la noche. Medea y Jasón debaten su agravio por última vez. Ella le pide la gracia del odio a sus hijos, y con ellos y la nodriza que los trae se retira. Jasón llama a sus soldados; gritan, despavoridas, las mujeres del interior, prende el incendio tras el muro, y en el público se promueve una oleada de admiración mal contenida por la ansiedad expectante del desenlace. Medea aparece en el carro que la arrebata a los cielos tirado por simbólicos dragones, obra del acusado talento de decorador de Piti Bartolozzi, digna hija de su padre, el gran dibujante. Jasón contiene el ímpetu de sus aguerridas tropas, que vienen dispuestas, ataviadas de color pardo y azul, con oros metálicos. Gritan. Quieren matarla. Bárbaramente inmola Medea a sus hijos ante los ojos del padre y aun le arroja en prenda espantosa el cadáver tierno del niño, en tanto la voz poderosísima de Borrás, en agudo clamor, grita a su esposa terrible : «Vete por los hondos espacios del alto firmamento a atestiguar por donde pases que no hay dioses». La orquesta lanza los últimos acordes de la obertura de "Alceste». Con las postreras notas vese a Borrás correr con el hijo muerto en brazos, y la multitud se lanza furibunda, gesticulante y ululante, tras el carro de Medea. Se apaga el fuego y el humo se disipa. En la noche 
quieta, tras el grito con que el público ha secundado el grito de la muchedumbre escénica, ha habido un silencio de expectación y luego un clamor de entusiasmo delirante, un bravo rotundo sobre el teatro. Un viva estentóreo ha saludado la presencia de Margarita Xirgu, que corresponde con los brazos en alto. Después, uno tras otro, han salido al hemiciclo todos los intérpretes de "Medea»: justo es citar a dos actores del coro, Enrique Guitar y Enrique Alvarez Diosdado. Luis Torner, José Cañizares, Fernando Porredón, Ricardo Merino, y a los directores de masas Fernando Aguirre, Pilar Muñoz, Eloisa Vigo, Amanda Nalda, Manchuli Sanz, Laura Bove, Marín Arias; a P. López Lagar, en el mensajero; a Miguel Ortín y al experto regidor de escena; a cuantos, en fin, con abnegación y disciplina admirables han dado ejemplo, que ya no habrá que ir a buscar a los mejores conjuntos extranjeros. Suben a escena Unamuno, Paco Casas y Rivas Cherif, animador del espectáculó imponderable, amablemente hostilizados una y otra vez, entre el aplauso unánime, de los fogonazos del magnesio de los fotógrafos. El Himno nacional ha cerrado la fiesta. El presidente, con los ministros, ha acudido a felicitar personalmente a Margarita Xirgu y Enrique Borrás. Todos, actores, público e intérpretes, han salido confundidos en el entusiasmo general»?

Según A. Rodrigo, a raíz del estreno de El otro de Unamuno en 1932, una tarde, Fernando de los Ríos comentaba en un salón del Teatro Español de Madrid el olvido en que se tenía a Séneca como autor dramático. A la reunión asistía D. Miguel de Unamuno, que propuso: "Pues si Margarita quiere representar alguna tragedia yo se la traduzco». A este propósito, Margarita Xirgu recuerda: «Yo elegí Medea, que Unamuno tradujo con tanto desinterés que no quería cobrar los derechos de autor"; a las dos semanas, Unamuno entregaba a la actriz la versión castellana de la tragedia de Séneca, encargada expresamente por Cipriano Rivas Cherif, director de la compañía, para la primera representación en el Teatro Romano de Mérida, recién restaurado ${ }^{3}$. El mismo Miguel de Unamuno da algunos detalles sobre su traducción, en un comentario publicado en el diario Ahora, 22 de junio de 1933: «...La desenterré de su latín barroco para ponerla, sin cortes ni glosas, en prosa de paladino ro-

\footnotetext{
«Una representación memorable de la «Medea» de Séneca, en el teatro romano de Mérida», El Sol, 20 de junio de 1933. Ver también la crítica de M. FERNÁNDEZ ALMAGRO, "Representación de «Medea» en el teatro romano de Mérida», El Sol, 21 de junio 1933.

3 Ver A. Rodrigo, Margarita Xirgu, Barcelona, Círculo de Lectores, 1994, 265. La versión de Unamuno, titulada «Medea. Tragedia de Lucio Anneo Séneca, traducida sin cortes ni glosas del verso latino a prosa castellana por Miguel de Unamuno", puede verse en M. GARCíA BLANCO ed., Obras Completas de Don Miguel de Unamuno, Madrid, 1966-1971, vol. V (Teatro completo y monodiálogos), 1968, 827-856.
} 
mance castellano, lo que ha sido también restaurar ruinas...Pretendí con mi versión hacer resonar bajo el cielo hispánico de Mérida el cielo mismo de Córdoba, los arranques conceptistas y culteranos de Séneca, pero en la lengua brotada de las ruinas de la suya... En cuanto a la tragedia de Medea nada debo decir hoy aquí de la pasión de la terrible maga - bruja - desterrada que antes de desprenderse de sus hijos los sacrifica, vengadora, a un rencor infernal. Hay en esa pasión, tremenda, que tan bien comprendió el cordobés Séneca, maestro de Nerón, mucho de la tremenda pasión que agita las más típicas tragedias de la historia de nuestra España. ¿Inhumanidad? ¿Hay algo más humano que ella?» 4 . Unamuno había pasado por un periodo antibarroco y anticulterano, actitud que queda patente en su obra En torno al casticismo, típica de los miembros de la generación del 98 . Pero la generación del 27 había cambiado los valores de la estética literaria al reivindicar a Góngora y el culteranismo, y Unamuno declara su admiración por Séneca en 1933 con una aséptica traducción de su Medea. Así pues, Unamuno, al final de su vida, poco antes de su jubilación en 1934, rinde memoria al gran trágico latino, a pesar de que a mitad de su carrera no había reconocido su deuda con Séneca en su Fedra ${ }^{5}$.

Sobre el carácter de la obra, Unamuno comenta: «Yo no he hecho más que hablar a Séneca en castellano. Séneca no hizo más que explicar la historia de Medea. Pero Margarita Xirgu ha hecho Medea. Ha convertido este personaje, imaginario o real, en un ser vivo que se apodera de nosotros en cuerpo y alma» ${ }^{6}$.

Esta versión de Medea también triunfó en la Plaza de la Armería del Palacio Real de Madrid y en el Teatro Griego del Parque de Montjuïc en Barcelona. Con una versión escenográfica de cámara de Medea, a cargo de Sigfrido Burmann, se inició la temporada 1933-1934 en el Teatro Español de Madrid el 28 de octubre de 1933. En el verano de 1934 se celebró de nuevo en el Teatro de Mérida una «Semana Romana de teatro", representándose Medea y Electra. Finalmente, la obra también se representó en la Plaza del Palacio de Anaya de Salamanca, el 11 de septiembre de 1934, como preludio a los actos de la jubilación de Unamuno ${ }^{7}$.

\footnotetext{
4 M. DE Unamuno, «Séneca en Mérida», Ahora 22 de junio de 1933.

5 Ver A. Valbuena-Briones, «Séneca en el teatro de Miguel de Unamuno», en J.M. Lasagabaster ed., El teatro de Miguel de Unamuno, San Sebastián, 1987, 87-103, 102-103.

6 A. Rodrigo, op. cit, 1994, 464 ("Algunas opiniones sobre Margarita Xirgu», 460 ss.). Id., Ibid., 266.
} 


\section{LA MEDEA DE MARGARITA XIRGU EN MÉXICO, VISTA POR ANTONIN ARTAUD}

El 31 de enero de 1936, desde Santander, Margarita Xirgu y su compañía emprenden viaje rumbo a Cuba, primera etapa de su nueva gira de seis meses por tierras de América. El 14 de febrero debutan en La Habana, en el Teatro de la Comedia, pasando luego al Teatro Nacional, con obras de F. García Lorca y de Hofmannsthal. El 10 de abril la compañía llega a México, y M. Xirgu inaugura la temporada oficial del Palacio de Bellas Artes de la Ciudad de México con la presentación el 20 de abril ${ }^{8}$.

Antonin Artaud había llegado a México el 7 de Febrero de 1936 con la intención de visitar los restos de la civilización de los Aztecas y de los Toltecas, y se ganaba la vida dando conferencias y escribiendo artículos sobre cuestiones diversas. Algunos de estos estudios tienen por tema el teatro, como el artículo que publicó en el diario mexicano El Nacional el 7 de junio de 1936 bajo el título de "Una Medea sin Fuego», con ocasión de las representaciones en el Palacio de Bellas Artes de la obra de Séneca por la compañía de M. Xirgu. En noviembre de 1936, Artaud vuelve de México, y en abril de 1937, después de una cura de desintoxicación de láudano en una casa de salud, corrige las pruebas de su ensayo definitivo sobre filosofía teatral Le Théâtre et son Double, que aparecerá en febrero de $1938^{9}$.

Durante su viaje a México, Artaud se plantea especialmente la cuestión de la tragedia, llegando a afirmar en un artículo que «la forma más sublime de teatro es la tragedia» ${ }^{10}$. Asimismo, la representación de Medea sirve al dramaturgo para describir su visión del «universo trágico», un universo ligado a un mundo mítico poblado de monstruos ${ }^{11}$. Según Artaud, "La Medea de Séneca es un mundo mítico; la de Margarita Xirgu carece de fuego y está fuera de lugar. Los mitos no deben de ser empequeñecidos. Pues es así como se resigna uno a no ser más que un hombre, y he aquí un miserable antropomorfismo. Es así como se descubre uno hombre, y se

$8 \quad$ Id., ibid., 365 ss., 484.

- Ver H. GouHIER, Antonin Artaud et l' essence du théâtre, París, Vrin, 1974, 127-128.

10 A. ARTAud, «El teatro francés busca un mito», El Nacional 28 de junio de 1936. Probablemente Artaud viajó a México con su adaptación del Tiestes de Séneca, El Suplicio de Tántalo, ya acabada en noviembre de 1935. El 26 de febrero de 1936 Artaud pronunció una conferencia en la Universidad de México con el título «Surrealismo y Revolución», en la que el dramaturgo se refiere al mito de Tántalo y Atreo. Ver J.C. SÁNCHEZ LEón, op. cit., 1997.

${ }^{11}$ A. ARTAUD, "Una Medea sin Fuego", El Nacional, 7 de junio de 1936. El texto ha sido retranscrito al francés por Marie Dézon y Philippe Sollers, "Une Médée sans feu» (Oeuvres Complètes, París, Gallimard, ed. rev. y aum., VIII, 1980, 197-200). 
descubre al hombre, pequeño por tu tamaño, débil en su rumor, desnudo en fin. En esta tragedia, era necesario hacer saltar monstruos, hacer ver que se estaba entre monstruos; monstruos de la imaginación primitiva vistos a través del espíritu primitivo. No se acerca uno a los monstruos tan fácilmente. Jason y Medea son inabordables el uno para el otro: cada uno tiene su círculo, cada uno está en medio de un círculo. Jasón llega abriéndose paso entre los dioses; Medea también. Un dios frente a otro dios. En todo momento, la atmósfera del drama es la más alta. Por eso, los antiguos poseían todo un instrumental trágico: Coturnos, Maniquíes, Máscaras; simbolismo de las máscaras, las líneas y los ropajes. Y no era para que se les viera de lejos, era para superar, para matar la estatura del hombre». Según Artaud, "la particularidad del teatro moderno es que sistemáticamente se pierde la ocasión de representar una tragedia, es decir, de desgarrar verdaderamente la atención por medio del crimen. "Os invoco con una voz siniestra», dice Medea, una voz que llama a los crímenes, que es una invención y una imaginación de crímenes». Para el dramaturgo, "el teatro moderno es un teatro que hace trampa porque tiene miedo de tratar con las potencias que son, que existen, y que no hay que pretender esquivar».

A continuación, la dura crítica de Artaud a la representación de la Medea de Séneca por Margarita Xirgu versa especialmente sobre lo que el dramaturgo llama la "técnica material y decorativa» (decorado, vestuario, iluminación) y la "técnica fisiológica y psicológica» (voz, gesto, movimiento) de la tragedia, completando y resumiendo así elementos teóricos esenciales de sus manifiestos anteriores sobre el «Teatro de la Crueldad» ${ }^{12}$ :

- En cuanto al decorado, para Artaud, el objeto de la técnica de la tragedia es «engañar verdaderamente a los sentidos; para lo que primero es preciso no desesperarlos. El teatro es el mundo de la ilusión verdadera. La imaginación del espectador necesita creer en lo que ve. Darle decoraciones que tiemblan y que por encima de todo están pintadas de modo de engañar al ojo, no es engañar al ojo, es desesperar y disgustar al ojo, que se reiría si pudiera». Artaud advierte que «en la Medea de la Xirgu se han colgado tres carcomidos trapos de sacudir, que pretenden

12 A. ARTAud, «Le Théâtre et son Double», Oeuvres Complètes, IV, 1978, 82 ss., especialmente 90-95 («Le spectacle», «Le langage de la scène»; «La lumière-les éclairages»; "Le costume»; "Les objests-les masques-les accesoires»; "Le décor»; "L'acteur»; "L'interpretation») y 119122 ("Au point de vue de la forme»). En la adaptación y proyecto de montaje del Tiestes de Séneca entre 1933 y 1935, Artaud también había desarrollado elementos teóricos esenciales del «teatro de la crueldad» sobre el espacio escénico, el sonido y la interpretación, a partir de sus dos Manifiestos. Ver J.C. SÁNCHEz LEÓN, op. cit., 1997. 
evocar montañas ciclópeas. Y, para acabar, estas montañas son estilizadas. No trago - prosigue el dramaturgo - esta estilización hecha a base de trapos de sacudir, sucios. Fue Gordon Craig quien inventó el sistema en Europa. Pero literalmente ya nos colmaron en Europa las estilizaciones a la Gordon Craig». Por otro lado, según Artaud, "desde el punto de vista decorativo, la tragedia tiene también signos simbólicos, de donde han nacido, por ejemplo, los pabellones de los lictores, la cruz, el caduceo de Mercurio. Los ejércitos romanos marchaban detrás de un bosque de signos. ¿Donde estaban - se pregunta Artaud - las insignias simbólicas de la Medea del Palacio de las Bellas Artes? Artaud considera que «los objetos sobre la escena deben ser tomados por lo que son. Es el único medio, según mi criterio, de crear la ilusión escénica. No debe tomarse un trapo de sacudir y querer hacernos creer que es una montaña, sino tomar una montaña y utilizarla como un trapo. Ciertamente, no se puede transportar una montaña sobre la escena, pero se puede transportar un espejo y reflejar en él una montaña. La técnica consiste en no tratar de representar lo que no se puede representar. Todas las tradiciones auténticas del teatro han despreciado siempre la realidad, pero nunca la han sustituido por un artificio raquítico. Por donde quiera el actor representa con objetos de la vida: mesas, sillas, armarios, escalas, y se limita con ellos; el resto, lo gesticula. El decoración está en sus brazos, en su cuerpo, en sus pies, en sus manos, en su ojo, y principalmente en su cara, cambiante como un paisaje en que las nubes juegan a ocultar el sol. Pero esto no impide que los objetos naturales, por un verdadero desacuñe psicológico, cambien de valor cambiando de plano; y cambian de plano porque su situación psicológica es nueva, extraña, sorprendente, inesperada... "Los objetos sobre la escena se vuelven monstruos, a quienes la palabra, el gesto y el movimiento de los actores prestan un alma sobrenatural», concluye Artaud. La representación de Medea en Mérida se había realizado en un decorado natural, bajo la supervisión del escenógrafo Sigfrido Burmann y con la colaboración de Piti Bartolozzi en los efectos especiales de la escena final de la obra, cuando Medea asciende a los cielos en un carro de fuego tirado por dragones. El mismo Burmann preparó una versión de cámara de la obra, que se estrenó el 28 de octubre de 1933 en el Teatro Español de Madrid. Según A. Rodrigo, al exponer la obra a la luz de las baterías, perdía la grandiosidad espectacular de la naturaleza, pero en cambio permitía apreciar con fidelidad la labor de Margarita Xirgu y la pasión arrebatadora, gestual, que infundía al trágico $y$ legendario personaje ${ }^{13}$.

\footnotetext{
13 A. Rodrigo, op. cit., 1994, 266.
} 
- En cuanto al vestuario, Artaud considera que «de un color aun más sucio (que los trapos del decorado) son los sacos que visten los criados que al entrar están a punto de caerse de bruces. Os recomiendo el coro - dice-, ese coro de guerreros con brazos de color de rosa, y que parece salido de un hospital de niños inválidos. Todos ellos visten un paño verde, como si para vestirlos hubieran saqueado 100 billares. El traje de Creonte es el más inverosímil de todos. Lleva en bandolera una sarta de hojas de acanto, cada una del tamaño de un muslo de elefante. Si con esta banda de hojas bárbaras se espera significar su realeza, esto quiere decir cuando mucho que se toma a los reyes por vagabundos borrachos. $Y$ si muchos reyes tienen en efecto hábitos de borrachos y almas degeneradas de vagabundos, los reyes míticos en cualquier caso deben darnos una imagen superior de la realeza. Los escenificadores del teatro moderno no tienen ya el sentido de lo que es el verdadero gobierno monárquico, como tampoco tienen el de lo que es la tragedia", en probable alusión al director artístico de la compañía Xirgu, Cipriano Rivas Cherif. El vestuario de la representación de Mérida había sido diseñado por el hermano de Margarita, Miguel Xirgu: Medea viste de rojo; el coro, con túnicas amarillas y capas verdes y los soldados de Jasón visten de color pardo y azul, con oros metálicos.

- En cuanto a la iluminación, piensa Artaud que «no es haciendo jugar alumbrados de music-hall moderno sobre los trapos de sacudir antes descritos, como se llegará a darnos una idea de la atmósfera sobrenatural de espanto que desborda el texto verdaderamente mágico de Séneca, quien era un iniciado auténtico, mientras que los tragediantes modernos no son más que títeres y saltimbanquis». Para el dramaturgo, «la luz recamando todo como un encanto, ayuda a la ilusión o a la desilusión. Pues la luz tiene un valor moral; no está hecha solamente para alumbrar los objetos». En la representación de Mérida se utilizaron reflectores al caer la tarde; en la versión de cámara de Medea también se utilizaron baterías.

- En cuanto a la interpretación, considera Artaud que "por lo que toca a la técnica fisiológica que se propone cambiar la voz humana por medio del conocimiento del aliento y de sus puntos de apoyo musculares, debo decir que en esta Medea se la presenciaba menos. La Xirgu grita uniformemente y sin matiz, sin un tono de voz que nos sacuda las entrañas y nos haga saltar el alma en el cuerpo. No parece pensar que se puede ajustar el diapasón de la voz humana hasta hacerlo cantar como un verdadero órgano. Hay medios de hacer saltar la voz, de hacerla temblar como un paisaje. Hay toda una escala de la voz». Por otra parte, según Artaud, "la tragedia nace del mito. Toda tragedia es la representación de un gran mito. El lenguaje de los mitos es el símbolo y la alegoría. La alegoría 
se manifiesta por signos. Hay un idioma de signos que forma parte de la técnica plástica y decorativa de la tragedia. La representación de la Xirgu carece de signos alegóricos. No posee sino dos o tres gestos invariables, de la mano en la cabeza o los brazos en cruz". Finalmente, considera el dramaturgo que «en cuanto a la técnica psicológica, allí es donde interviene el don de la poesía: ella es la que permite que Jasón llegue arrollando monstruos cuando entra con el garbo de un dios. Pues se puede hacer subir a los dioses a escena, se pueden crear círculos mágicos en torno de los personajes inabordables de un mito realmente figurado. Pero, lo repito, para ello hace falta un don. El principio consiste en introducir a la escena la lógica irracional y monstruosa de los sueños, que en una mano hace ver una cara, y que de un suspiro exhalado junto a la oreja, saca la idea del paso de un huracán. Es una técnica de imágenes que en el lenguaje corriente da origen a la metáfora. Con gestos de doble fondo, el actor trágico camina rodeado de metáforas, creadas constantemente por su voz, sus gestos y sus movimientos".

- En cuanto a la música de escena, Artaud no hace ningún comentario. En la representación de Mérida, se interpretaron algunas obras del compositor alemán Gluck (1714-1787), caracterizadas por su sobriedad: Ifigenia en Áulide (Ópera de París, 1774, a partir del libreto de Du Rollet); Orfeo, obra con la que Gluck inicia la renovación de la ópera italiana (Viena, 1764; París, 1774, en francés), y Alceste (París, 1776, en francés). La dirección de la orquesta, la Filarmónica de Madrid, corrió a cargo de su creador en 1915, el maestro Bartolomé Pérez Casas.

Así pues, la crítica que realiza Antonin Artaud en junio de 1936 de la representación de la Medea de Séneca por la compañía de M. Xirgu, tiene una gran importancia desde el punto de vista de la teoría teatral, ya que sirvió al dramaturgo para completar y resumir algunos conceptos definidos en sus dos Manifiestos sobre el «Teatro de la Crueldad» (1932-1933), en concreto sobre "la técnica de la tragedia», es decir, el "elemento físico y objetivo" del "teatro de la crueldaad". 